\title{
Effective governance of transnational adaptation initiatives
}

\author{
Adis Dzebo ${ }^{1,2}$ \\ Accepted: 23 May 2019 / Published online: 5 June 2019 \\ (C) The Author(s) 2019
}

\begin{abstract}
Transnational climate governance has mainly been preoccupied with climate change mitigation, both in practice and as studied in academic literature. However, transnationally governed adaptation initiatives are emerging and increasing in scale. This paper analyses the effectiveness of transnational adaptation initiatives as a particular knowledge gap in this changing evolving governance landscape. Based on a new dataset of 40 initiatives that are governing adaptation across borders and that include non-state actors, it offers an overview assessment. It asks: do transnational adaptation initiatives achieve their stated goals and objectives, and which factors explain their ability to contribute to effective climate change adaptation? Drawing on transnational climate and sustainable development governance literature, an analytical framework is developed to assess to what extent 'actors', 'process', 'institutional design' and 'context' can explain effective outcomes. The assessment found that while almost two-thirds of the initiatives were highly effective in achieving goals and objectives by producing outputs, only one-third were highly effective in achieving outcomes, in the sense of leading to substantial change in behaviour of target groups. Where initiatives are effective, the main factors determining success are strong leadership and orchestration, good process management and staff resources, a focus on standard-setting and service provision rather than knowledge transfer, a high level of institutionalisation through binding rules for partners, and good coordination with international regimes. Perhaps less expected in view of the voluntary involvement of actors in transnational adaptation initiatives, initiatives based on 'hard' functions (i.e. standard-setting and service provision as opposed to knowledge transfer) and binding rules for partners were found to be more effective.
\end{abstract}

Keywords Transnational governance $\cdot$ Adaptation $\cdot$ Non-state actors $\cdot$ Effectiveness

\section{List of abbreviations}

CSA Climate-Smart Agriculture

FAO Food and Agriculture Organization of the United Nations

FTE Full-time equivalent

Adis Dzebo

adis.dzebo@sei.org

1 Stockholm Environment Institute, Linnégatan 87D, 11523 Stockholm, Sweden

2 Copernicus Institute of Sustainable Development, Utrecht University, Princetonlaan 8a, 3584 CB Utrecht, The Netherlands 


$\begin{array}{ll}\text { GACSA } & \text { Global Alliance for Climate-Smart Agriculture } \\ \text { GAFCA } & \text { Global Aggregator for Climate Actions } \\ \text { GPSC } & \text { Global Platform for Sustainable Cities } \\ \text { IO } & \text { International Organisation } \\ \text { IPCC } & \text { Intergovernmental Panel on Climate Change } \\ \text { MoU } & \text { Memorandum of Understanding } \\ \text { NAP } & \text { National Adaptation Plan } \\ \text { NGO } & \text { Non-governmental Organisation } \\ \text { SAN } & \text { Sustainable Agriculture Network } \\ \text { UNCBD } & \text { United Nations Convention on Biological Diversity } \\ \text { UNEP } & \text { United Nations Environment Programme } \\ \text { UNFCCC } & \text { United Nations Framework Convention on Climate Change } \\ \text { WFP } & \text { World Food Programme } \\ \text { WMO } & \text { World Meteorological Organization }\end{array}$

\section{Introduction}

Two significant traits of transnational climate governance research today are that most initiatives are located in the global North (Roger et al. 2015) and that the plethora of empirical observations focus on climate change mitigation (Chan et al. 2018; Bulkeley et al. 2014). In contrast, adaptation to climate change has been given limited attention. Historically, the focus of the research community and practitioners has been on direct impacts and environmental modelling, generally delimited to national borders, leading to the perception that adaptation does not constitute a global public good and thus is not a legitimate or urgent issue for global governance (Ford and Berrang-Ford 2011; Berrang-Ford et al. 2011; Benzie and Persson 2019). However, following the 2015 Paris Agreement, adaptation in the United Nations Framework Convention on Climate Change (UNFCCC) is being discussed as a challenge faced by all, with local, subnational, national, regional and international dimensions (Persson and Dzebo 2019). Researchers are increasingly turning their focus to global aspects of adaptation, including the overarching institutional architecture (Magnan and Ribera 2016; Persson et al. 2009; Biermann and Boas 2010; Khan and Roberts 2013), finance (Dzebo and Stripple 2015), development (Ayers and Dodman 2010) and political economy (Sovacool et al. 2015; Khan 2013). However, as Ford et al. (2015) note, there is a lack of approaches and indicators that focus on whether and how adaptation is taking place globally.

Understanding how adaptation governance is shared across levels and actors is important because it has implications for the quality of governance, its effectiveness and its legitimacy (Karlsson-Vinkhuyzen and Vihma 2009; Roggero et al. 2019). That transnational regimes and new forms of governance have emerged is well established in the literature. But while adaptation governance seems to increasingly involve new types of actors (Isoaho and Surminski 2015; Klein et al. 2017), the interaction between state and non-state actors across national borders and the effectiveness, normative impact, and distributional consequences (Abbott 2012) of this interaction on the governance of adaptation are insufficiently explored by empirical research.

This paper aims to fill this gap by analysing the effectiveness of transnational adaptation initiatives. It offers an assessment of 40 initiatives, compiled in a new dataset, that are governing adaptation across borders and that include non-state actors. It asks: do transnational 
adaptation initiatives achieve their stated goals and objectives, and which factors explain their ability to contribute to effective climate change adaptation? The analysis focuses on what the initiatives are producing in terms of outputs and outcomes, the latter of which refers to changing behaviour of actors, and does not address ultimate impact. The database has been constructed through a literature review and analysis of existing work on global climate action, and the analysis is complemented by 31 semi-structured interviews with stakeholders in the initiatives.

Assessing effectiveness in environmental regimes is fraught with difficulties (Mitchell 2008). This paper limits itself to an evaluation of outputs and what outcomes they lead to, as opposed to impact. It analyses the role of four independent variables: actors, process, institutional design, and context. While such a functionally orientated analysis can indicate and seek to explain how and why adaptation initiatives perform in certain ways across multiple dimensions, it needs to be complemented in the future to consider also how power relations between various actors and structures influence the performance and design of initiatives. Nevertheless, this paper contributes to this Special Feature by, together with Chan and Amling (2019), offering initial frameworks for, and results of, empirical analyses of the effectiveness of current transnational adaptation governance, as an element of broader global adaptation governance.

The next section explains the methodology for data collection and analysis. Section three conceptualises effectiveness and how it can be applied to transnational governance. Section four introduces the analytical framework for studying independent variables. Section five starts with a discussion of the emergence of transnational adaptation initiatives and then presents the assessment. Section six explains the results with the support of the analytical framework. The paper concludes with reflections on the implications for transnational governance and the need for further research.

\section{Methodology}

To address the research questions, a new database was created that includes 40 initiatives that govern adaptation transnationally and that work across several topics, including cities and regions, agriculture and biodiversity, water management and broader cross-sectoral resilience (Table 1). Building on Bulkeley et al. (2014) and Dzebo and Stripple (2015), the criteria for including initiatives were if they (1) explicitly seek to reduce vulnerability to impacts of climate change, (2) operate transnationally, and iii) seek explicitly to govern a constituency, be that participating members or a wider audience.

Data were collected through a review of existing databases and lists, including the Lima-Paris Action Agenda, the UNEP Climate Initiatives Platform, the Global Aggregator for Climate Action (GAFCA) database (Chan et al. 2018), initiatives in the area of human settlements and adaptation (UNFCCC 2017) as well as a broader literature review and web search. ${ }^{1}$ Given that research on transnational adaptation governance is at an early stage, the approach of this paper does not assume full representativeness in its data sample. For each individual initiative, policy and other documents were collected. While this is mainly a desk-based study, 31 semi-structured interviews ${ }^{2}$ were undertaken with actors working

\footnotetext{
1 The initiatives were reviewed and entered into the database between January and June 2017.

${ }^{2}$ Nine out of 40 initiatives did not respond to multiple requests for interview.
} 
Table 1 List of transnational adaptation initiatives included in the database

\begin{tabular}{|c|c|}
\hline 100 resilient cities & Global Platform for Sustainable Cities \\
\hline Adaptation Learning Mechanism & Global Resilience Partnership \\
\hline Africa Climate-Smart Agriculture Alliance & Global Water, Climate and Development Programme \\
\hline Africa Adapt & $\begin{array}{l}\text { Great Green Wall for the Sahara and the Sahel Initia- } \\
\text { tive }\end{array}$ \\
\hline Arctic Adaptation Exchange & $\begin{array}{l}\text { Initiative for Adaptation of African Agriculture to } \\
\text { Climate Change }\end{array}$ \\
\hline Asian Cities Climate Change Resilience Network & Initiative for Coffee and Climate \\
\hline C40 Cities & InsuResilience \\
\hline Caring for Climate & Local Governments for Sustainability (ICLEI) \\
\hline Cities alliance & Making Cities Resilient Campaign \\
\hline Cities Climate Finance Leadership Alliance & Megacities Alliance for Water Under Climate Change \\
\hline Climate technology centre and network & NAP global adaptation network \\
\hline Climate-Smart Agriculture (CSA) Booster & $\begin{array}{l}\text { Network Of Regional Governments For Sustainable } \\
\text { Development }\end{array}$ \\
\hline Compact of Mayors ${ }^{\mathrm{a}}$ & Partners for Resilience \\
\hline Coral Triangle Initiative & R4 Rural Resilience Initiative \\
\hline Covenant of Mayors & Regions of Climate Action \\
\hline Emerging and Sustainable Cities Program & Resilience Tools \\
\hline Evergreen Agriculture Partnership & ResilientAfrica network \\
\hline Global Alliance for Climate-Smart Agriculture & Southern Voices \\
\hline $\begin{array}{l}\text { Global Facility for Disaster Reduction and Recov- } \\
\text { ery }\end{array}$ & Sustainable Agriculture Network \\
\hline Global Framework for Climate Services & Transformative Actions Program \\
\hline
\end{tabular}

${ }^{\mathrm{a}}$ The two initiatives Compact of Mayors and Covenant of Mayors have subsequently merged into one initiative called Global Covenant of Mayors. In this study, they have been assessed separately

with adaptation-related issues within the initiatives. The interviews helped bring out some of the more intangible aspects of an initiative as well as complementing the literature and documentary review.

For analysing the data and to assess effectiveness, the paper draws on the framework developed by Liese and Beisheim (2014). Each initiative is assessed on a three-point scale (high, medium, low-see Table 2), and outputs and outcomes were assessed based on the extent to which they contributed to reaching the objective(s) of the initiatives (note that impact and problem solving was not assessed). However, the variety of transnational initiatives governing adaptation in diverging socio-economic sectors poses challenges for a comparative assessment. For example, some of the initiatives focus on several, and sometimes competing, thematic issues. Furthermore, it is not always clear-cut whether outputs aim to improve climate adaptation directly or have other aims and meet adaptation objectives indirectly (Sovacool et al. 2015). Thus, it is far from certain against which benchmarks initiatives should be assessed when objectives and targets diverge. Further, this assessment does not consider distributive impacts or the political economy of adaptation initiatives (see e.g. Sovacool et al. 2015; Berrang-Ford et al. 2011). It assesses all outputs that have an objective to decrease vulnerability in human and natural systems from the impacts of climate change. 
Table 2 Qualitative indicators of regime effectiveness. (Source: Liese and Beisheim 2014: 21)

\begin{tabular}{|c|c|c|c|}
\hline & \multicolumn{2}{|l|}{ Goal attainment } & \multirow{2}{*}{$\begin{array}{l}\text { Problem solving } \\
\text { Impact }\end{array}$} \\
\hline & Output & Outcome & \\
\hline High & $\begin{array}{l}\text { Provision or adoption of } \\
\text { knowledge, standards, } \\
\text { services as envisioned in the } \\
\text { stated goals }\end{array}$ & $\begin{array}{l}\text { Substantial change in behaviour } \\
\text { of targets, extensive application/ } \\
\text { implementation of knowledge, } \\
\text { standards, services }\end{array}$ & $\begin{array}{l}\text { Substantial contribution to } \\
\text { solution of problem }\end{array}$ \\
\hline Medium & $\begin{array}{l}\text { Substantial policy papers and } \\
\text { some provision of knowl- } \\
\text { edge, standards, services, } \\
\text { but failure to achieve all } \\
\text { stated goals }\end{array}$ & $\begin{array}{l}\text { Some change in behaviour of } \\
\text { targets, some application or } \\
\text { implementation of knowledge } \\
\text { standards, services }\end{array}$ & $\begin{array}{l}\text { Some contribution to solu- } \\
\text { tion of problem }\end{array}$ \\
\hline Low & $\begin{array}{l}\text { Mere paperwork and meetings } \\
\text { with no or few results }\end{array}$ & $\begin{array}{l}\text { No or low change in behaviour of } \\
\text { targets, hardly any application/ } \\
\text { implementation of knowledge, } \\
\text { standards, services }\end{array}$ & $\begin{array}{l}\text { No or low contribution to } \\
\text { solution of problem }\end{array}$ \\
\hline
\end{tabular}

The assessment was based on documents, both internal and external, interview data, as well as academic and grey literature. As a first step, a qualitative analysis of outputs and how they relate to an initiative's goals was undertaken. Outputs are here defined as direct activities of an initiative, which include tangible and attributable products, such as project reports, policy briefs, academic publications, events and workshops, analytical tools and frameworks, databases, and training manuals. While outputs do not guarantee problem solving, nor necessarily result in desired behavioural changes, they are a precondition for achieving effective outcomes and subsequent impact. Therefore, assessing output performance remains an important first step (Chan et al. 2018).

As a next step, the study assessed to what extent an initiative's outputs were managed to achieve behavioural change. For example, if an actor, such as a government ministry, took up a decision-support tool as a method for making decisions or writing legislation, this was coded as a desired change in behaviour. Initiatives can also draft joint principles and use advocacy instruments and campaigning to create outcomes. Assessment of outcomes was done through review of internal and external documents and complemented with interviews when available.

This paper does not make any attempts to establish causality or attribution and therefore avoids discussing the initiatives' impact. For adaptation particularly, a key issue is that biophysical and socio-economic, as well as spatial and temporal, context affect impacts of adaptations (Adger et al. 2005). A dense web of complex causal relations makes it almost impossible to assign an initiative's actions to long-term impact.

\section{Transnational governance regime effectiveness}

What is already known about effectiveness of transnational governance regimes? Regime effectiveness focuses on the extent to which institutions achieve stated objectives (Mitchell 2008). Standard approaches to effectiveness compare actual performance of a regime with the counterfactual, i.e. what would have happened if the regime were not in place (Young 2011). Mitchell (2008) also points to the actual-versus-aspiration approach as a 
complement to actual-versus-counterfactual. A typical approach assesses behavioural change and change in environmental quality (Mitchell 2008; Underdal 2001; Underdal and Young 2004). Different dimensions of effectiveness can be grouped in a threefold typology of output, outcome and impact (Easton 1965) as sequential stages in a causal chain (Miles et al. 2001), as adopted above. An environmental regime can be assessed through a focus on outputs, the regulations created to operationalise the regime, and the outcomes and changes in behaviour of the involved actors. This is usually referred to as 'goal attainment'. Effectiveness can also be assessed in terms of a regime's problem-solving capacities (i.e. measurable improvement of the environment), via a conception of an ideal outcome or a collective optimum as set by the institutions involved (Mitchell 2008; Young 2004, 2011). Goal attainment is a minimum condition for effectiveness (Skjaerseth et al. 2006).

Effective goal attainment can change not only the behaviour of actors and their interests, but also the policies and performance of an initiative. However, goal attainment is not necessarily significant for broader institutional effects because the problem-solving dimension is about establishing a causal relation between the regime and the biophysical environment (Underdal 2001). As a counter-proposal Keohane et al. (1993) suggest focusing on the observable political effects of institutions. Thus, rather than focusing on the ability of transnational climate governance to improve actual environmental performance, potential impact could be visible in terms of shaping the system of rules and rule-making at the heart of the global response to climate change impacts (Bulkeley et al. 2014).

The notion of transnational governance regimes has emerged from the notion that states are no longer the exclusive source of regulatory global authority (Vogel 2008) and that private authority is emerging alongside traditional governance (Green 2013). Transnational interactions involve agreements between states and a variety of non-state actors such as NGOs, foundations, companies, research institutions, or transnational associations, on specific governance objectives and on means to advance them (Andonova 2014; Andonova et al. 2009; Bäckstrand 2008). These interactions are governed across multiple scales, borders and sources of authority, which rely on coordination through networks and markets (Schout and Jordan 2005; Treib et al. 2007).

Much of the literature on transnational climate governance assumes that non-state actors increase the effectiveness of governance because they bring in resources and knowledge that public actors lack (Jägers and Stripple 2003; Biermann et al. 2009; UNEP 2015; Hsu et al. 2016; Chan and Amling, 2019). For example, Cole (2015) argues that the best chance of progress on stabilising the climate is a polycentric approach to climate governance. Several studies have attempted to measure the effectiveness of non-state climate action (Chan et al. 2018; Hsu et al. 2015; Widerberg and Pattberg 2014). Nevertheless, there is still doubt about the long-term performance and sustainability of transnational climate governance (Jordan et al. 2015). Furthermore, much of this work focuses on climate change mitigation, and there is a lack of knowledge on adaptation as a global challenge (Tompkins et al. 2018; Ford et al. 2015) and what this means for transnational governance.

\section{Analytical framework}

Existing climate and sustainable development governance literature has also considered what conditions lead to effective outputs and outcomes. Below, an analytical framework is presented, drawing on this literature. Four broad categories are derived from this review, suitable for a 'medium-N study': actors, process, institutional design and context. 
Within the actors category, key factors for the success of an initiative are seen to be an optimal mix of partners, and the extent to which leadership is shown by both individuals and organisations (Pattberg and Widerberg 2016). Other factors considered important in the literature include a combination of willingness and capabilities among partners, the extent of partners' resources, and, in particular, engagement on the part of the most powerful and influential members of the initiative (Beisheim and Campe 2012; Beisheim 2012). On the other hand, large power-asymmetries between actors can be detrimental (Newell et al. 2012). Internal participatory structures, the broad characteristics of the participants, and fairness and equity, are particularly relevant for successful adaptation (Adger et al. 2005; Paavola and Adger 2006). With regard to leadership, a powerful orchestrator is considered a key ingredient in effective governance (Abbott and Snidal 2009; Chan and Amling 2019). For example, international organisations (IOs) or other appropriate authorities can support and steer transnational schemes (Abbott 2012; Abbott et al. 2015). It is, however, unclear what exactly is required of an 'orchestrator' to deliver effective outcomes (Glasbergen 2010).

Second, process implies that efficient management of the initiative is an important design feature of its effectiveness. A sufficiently funded, independent secretariat with fulltime staff, a coherent management strategy with a clear decision-making framework, common strategic plans, clear division of roles and responsibilities, and multilevel forums to coordinate funding and resources have been identified as effective management structures (Szulecki et al. 2011; Aylward et al. 2003). Pattberg and Widerberg (2016) argue that a good structure for process management includes staff focusing exclusively on achieving the objectives of the initiative and on ensuring effective communication between initiative members.

The third category is institutional design. It implies that the level of institutionalisation matters for effectiveness. More specifically, Liese and Beisheim (2014: 26) argue that obligations (clear and binding rules), precision in norms (meaning that rules and commitments are strictly enforced and that there is a clear and unambiguous mandate for actors), and delegation (meaning that there are external monitoring and evaluation functions) are all key to effective transnational initiatives (see also Abbott et al. 2000). A high level of institutionalisation is important for capacity building and institutional learning, stronger accountability and enhanced transparency (Pattberg and Widerberg 2016).

Lastly, with regard to context, Pattberg and Widerberg (2016) argue that meta-governance is an appropriate lens through which a fragmented governance system should be assessed. For meta-governance, i.e. organisation of self-organisation, or the regulation of self-regulation (Jessop 2011), authors draw attention to managing plurality with the aim of inducing more coherence in institutional fragmentation (Derkx and Glasbergen 2014; Biermann et al. 2009). Pattberg and Widerberg (2016) argue that initiatives should be assessed on how they liaise with each other as well as with other institutions dealing with related problems. In the case of transnational adaptation initiatives, this means determining how aligned they are with key principles of international regimes such as the UNFCCC, Agenda 2030 and the Sendai Framework for Disaster Risk Reduction. 


\section{Assessment of transnational adaptation initiatives}

\subsection{The emergence of transnational adaptation governance}

The local and national dimensions of adaptation are well understood after decades of natural and social science research, including reviews by the Intergovernmental Panel on Climate change (IPCC). Climate impacts are locally differentiated, climate vulnerability depends on local context, and successful adaptation is often enabled by local knowledge and support (IPCC 2018). However, climate change impacts, and adaptation measures taken to address these impacts, that may be experienced locally have cross-border and sometimes even global repercussions (Challinor et al. 2018; Hedlund et al. 2018). In addition, adaptation actions, even those taken at the local to national level, are shaped and steered by a governance system made up of actors who operate transnationally and globally. In a study on adaptation finance, Dzebo and Stripple (2015) found that transnational adaptation governance is emerging under a 'shadow of hierarchy', consisting mainly of loosely formed initiatives, which are shaped by 'softer' forms of governance such as information sharing and capacity building (see also Chan and Amling 2019).

Under the UNFCCC, the 2015 Paris Agreement on Climate Change introduces the global goal on adaptation: to enhance adaptive capacity, strengthen resilience and reduce vulnerability to climate change, with a view to contributing to sustainable development and ensuring an adequate adaptation response. The Paris Agreement also recognises that adaptation is a global challenge faced by all with local, subnational, national, regional and international dimensions (UNFCCC 2015). In addition, the UNFCCC has emphasised that adaptation is intrinsically linked to broader sustainable development, including agreements such as the Sustainable Development Goals and the Sendai Framework for Disaster Risk Reduction (UNFCCC 2018).

Both Dzebo and Stripple (2015) and Klein et al. (2017:13) define this development as an emerging fourth era of adaptation governance, in which non-governmental organisations, civil society and private actors (particularly small-to-medium enterprises), are increasingly held up as potential key players. Thus, the adaptation regime can be understood as involving a range of actors and forms of authority working across diverse issues and concerned with establishing and contesting what is entailed in the legitimate social purpose of adapting to climate change. Governance can take place directly, through steering actors towards explicit goals, though it may also involve more discursive and normalising practices such as exchange of knowledge, ideas and beliefs (Bulkeley et al. 2014).

\subsection{Are transnational adaptation initiatives achieving their goals?}

To what extent are these emerging transnational adaptation governance initiatives achieving goals and having an effect? The results of the assessment are presented below.

The 40 transnational initiatives are for the most part manifestations of networked governance, with most initiatives involving more than two different actor types. Thirty-five initiatives have a dedicated webpage and 5 are hosted by a larger web-portal, mainly through an IO. In terms of scope, 27 initiatives are global in scope, whilst 14 have a regional focus. In terms of their main approach with regard to climate change, 25 initiatives have adaptation as their main objective. In addition, 13 initiatives that have an equal adaptation and 


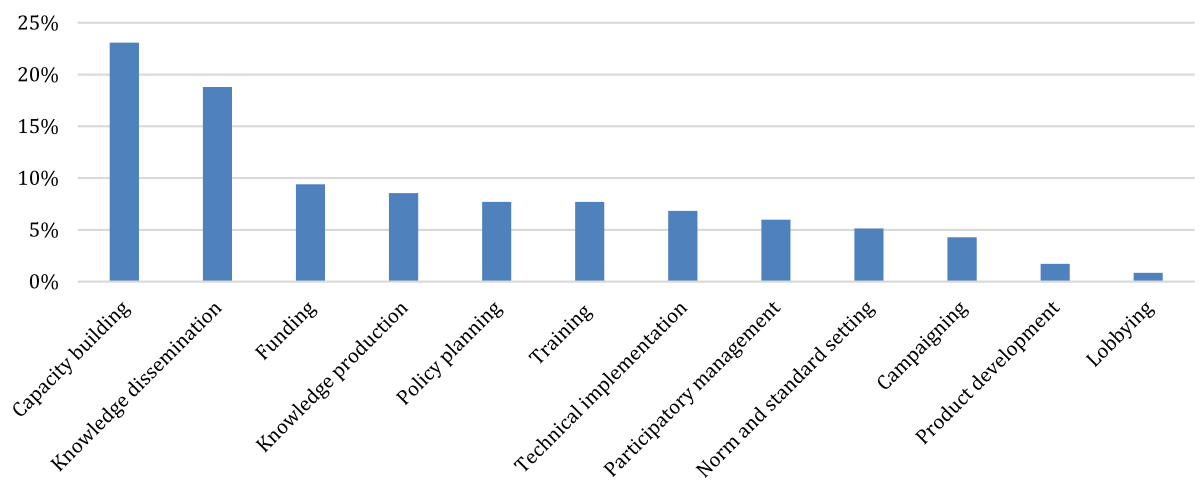

Fig. 1 Governance functions

mitigation approach and 3 initiatives focus mainly on mitigation activities with a lesser focus on adaptation.

The governance function of the initiatives was analysed based on their self-declared objectives and assessed along the twelve functional categories derived from Pattberg et al. (2012). As initiatives often focus on more than one governance function, the three most prominent functions were coded. Figure 1 shows the frequency of governance functions employed across the initiatives. It indicates that more than $40 \%$ of the initiatives focus on institutional capacity building and knowledge dissemination, followed by funding and knowledge production, which can be seen as 'soft' governance approaches. In contrast, 'harder' governance functions, such as norm and standard setting and technical implementation, are less prominent. These results are highly similar to Chan and Amling's (2019) findings.

Figure 2 presents the aggregated results of the analysis. It shows that the majority of initiatives reach high (almost two-thirds) or medium (almost one-third) effectiveness in terms of producing relevant outputs. However, when it comes to outcomes, almost two-thirds of the initiatives fail to generate substantial change in behaviour, by e.g. leading to extensive application and implementation of knowledge, standards and services. A selection of initiatives is discussed below to demonstrate how the assessment of effectiveness was done.

\subsubsection{High effectiveness}

In terms of delivering effective outputs, as Fig. 2 shows, almost two-thirds, or 25 initiatives, create outputs that correspond with the stated goals and objectives. With regard to effectiveness, the assumption here is that there is a causal relation between outputs and outcomes. From this it follows that only the initiatives that score high on output can lead to successful outcomes. Thus, of the 25 initiatives, 15 achieved effective outcomes, in the sense of leading to substantial change in the behaviour of targets. Initiatives that are effective are, in general, those that have been operating for more than 5 years. Of the 15 initiatives that scored high on goal attainment, 14 have been active since 2011 or earlier.

One successful initiative is Southern Voices, a coalition of climate networks and partners in the Global South. Its main adaptation-related output, the Joint Principles for Adaptation (Southern Voices 2015a) is a benchmark tool for adaptation planning and implementation and is applied in several countries. The partners are not only adhering to its 


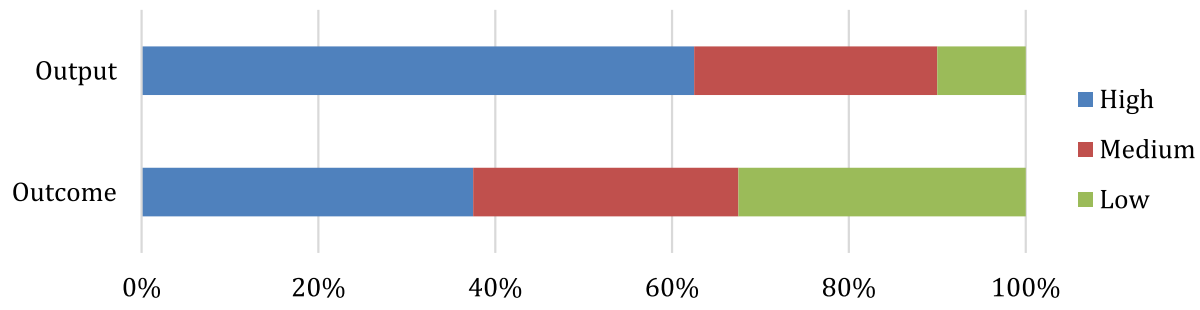

Fig. 2 Effectiveness of transnational adaptation initiatives

principles, but the principles are also used to influence external partners' behaviour. For example, in Guatemala, the tool has been translated into national climate law (Southern Voices 2015b). It has also been promoted by the UNFCCC as supplementary material for the National Adaptation Plan (NAP) process ${ }^{3}$ (UNFCCC 2012).

Another successful example is the R4 Rural Resilience Initiative, led by the World Food Programme (WFP), which among other things develops risk management strategies, such as insurance mechanisms, for improved livelihoods in rural Ethiopia, Senegal, Malawi, Zambia and Kenya. The initiative builds on proven achievements in terms of behaviour change (WFP and Oxfam 2017). Its outputs are well connected to the objective to increase communities' resilience to climate variability and risks. In addition, two independent impact evaluations have found that the initiative has demonstrated strong results in reducing the adverse impact of shocks on the food security of participant households, which amount to circa 300,000 people (Madajewicz et al. 2013; Dalberg 2016).

A third example is the Sustainable Agriculture Network (SAN), a consortium of NGOs working to conserve biodiversity and promote rural development. SAN is working with the Rainforest Alliance, ${ }^{4}$ a well-established certification system, in order to reach a broad set of target communities. SAN spans over 42 countries including 101 different crops and 1.2 million, mostly smallholder, farms on 3.5 million hectares. Evaluation reports found that the certification scheme has led to greater productivity and profitability, stronger ecosystems, and better livelihoods (SAN 2016; Milder and Newsom 2015). In addition, some academic studies have found positive effects from the certification scheme (Ochieng et al. 2013; Barham and Weber 2012).

\subsubsection{Medium effectiveness}

Ten initiatives achieve medium effectiveness. The Africa Adapt initiative, which aims to gather adaptation practitioners across Africa to share knowledge and insights, managed to become self-sustaining after funding from international donors ended through a successful output strategy. However, its aim to increase adaptive capacity among local communities and national decision makers is hindered because it does not provide insights on how knowledge production and dissemination is being applied.

\footnotetext{
3 http://www4.unfccc.int/nap/Guidelines/Pages/Supplements.aspx.

${ }^{4}$ From 1 October 2017 the partnership between SAN and the Rainforest Alliance was terminated and SAN has decided to change its business model to work directly with stakeholders rather than through certification.
} 
The Global Platform for Sustainable Cities (GPSC) is an initiative headed by the World Bank and founded in 2016. GPSC has developed multiple publications, arranged workshops as well as created diagnostic tools for cities that align well with its objective to promote an integrated approach to urban development by focusing on urban sustainability indicators, planning, and financing (GPSC 2016). However, while the initiative holds promise, it is too soon to assess effective outcomes. As one interviewee noted, it is easy to contribute to the global discourse on sustainable cities, but it is more difficult to implement measures locally on the ground.

\subsubsection{Low effectiveness}

Fifteen initiatives score low on effectiveness. Several of these manage to deliver knowledge outputs without a broader objective to build capacity and/or change behaviour of target groups. For example, the Adaptation Learning Mechanism has been active since 2007 and has collected a wealth of data on its knowledge platform, which is a part of its goal. However, beyond this, the platform does not reach the second part of its goal to build partnerships and indicates no proof of progress on this target.

Some initiatives show few or no outputs. For example, the Initiative for Adaptation of African Agriculture to Climate Change had its launch at the UNFCCC Conference of the Parties (COP) 22 in Marrakech in 2016 and enjoyed strong visibility. Its objective is to place the adaptation of African agriculture at the heart of climate change decision-making, and to foster implementation of solutions, particularly within the framework of the Global Climate Action Agenda. However, it has failed to build on its momentum, and little has been achieved since.

The Cities Climate Finance Leadership Alliance, an alliance of 40 public and private organisations working to mobilise climate finance, does not present any outputs on its webpage despite having a secretariat and several working groups. While the members independently might be successful, the alliance itself fails to show progress.

\section{Explaining the effectiveness of transnational adaptation initiatives}

The previous section shows that transnational adaptation initiatives are generally more effective when it comes to producing outputs rather than outcomes and-presumably, by implication-impact. On the other hand, it also shows that many initiatives are successful in changing behaviour internally across its partners, as well as of external target audiences. Why does effectiveness vary between initiatives? This section discusses to what extent the four variables of the analytical framework can explain effectiveness.

\subsection{Actors}

In terms of types of actors involved across the initiatives, Fig. 3 shows that NGOs are most commonly engaged in transnational adaptation. Almost $85 \%$ of the initiatives have at least one NGO as a partner, followed by IOs (around 70\%) and national governments (55\%), who are most often represented by their international development assistance organisations. It also shows that $50 \%$ of the initiatives involve the private sector. However, in terms of leading initiatives (Fig. 3), IOs are the most important actors, leading almost $45 \%$ of the initiatives, followed by NGOs, which lead more than $30 \%$. This indicates that transnational 


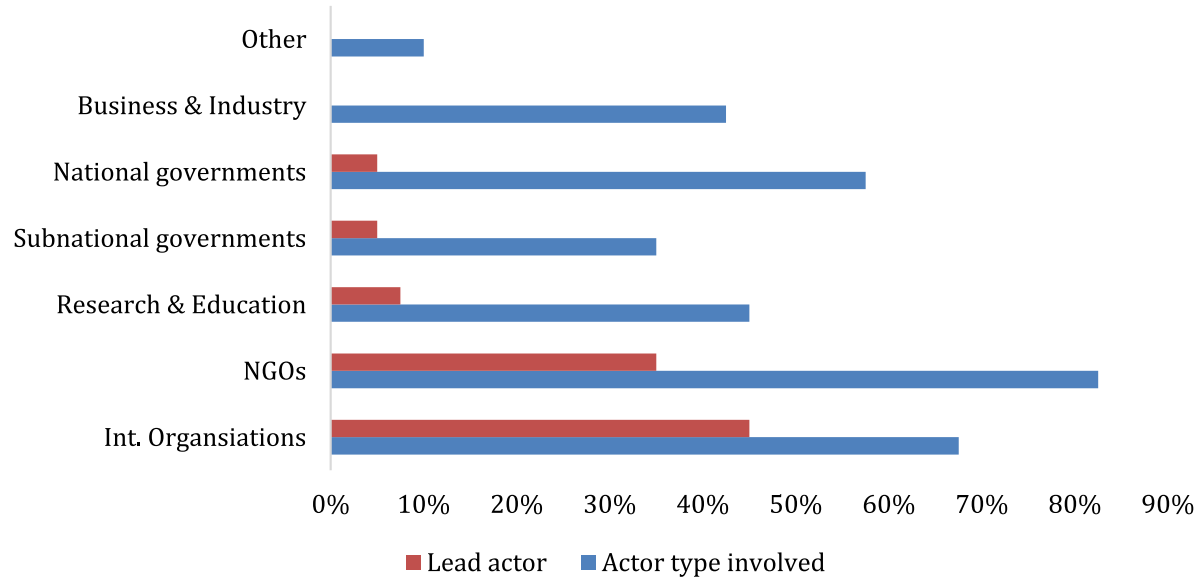

Fig. 3 Actor involvement in initiatives

adaptation is strongly anchored in the public sector and still has not fully emerged from the shadow of hierarchy (Dzebo and Stripple 2015; see also Héritier and Lehmkuhl 2008).

This becomes more evident when focusing only on those initiatives that are effective, where 8 out of 15 initiatives are led by IOs. This corresponds well with the theory on orchestration (Abbott and Snidal 2009). Actors that are leading these initiatives include the WFP, the World Bank, the World Meteorological Organization (WMO), and various other UN Agencies. IOs often have personnel and resources to support, steer and transform an initiative from idea to practice. However, IO leadership is no guarantee for effective outcomes and contribution to problem solving because more IO-led initiatives do not reach high effectiveness than do. Three reasons for this have been derived from the interviews. First, initiatives can be in their early phase and it is too soon to evaluate. Second, small initiatives can experience problems breaking through in a competitive environment. Third, funding has expired and the initiative is no longer a priority within the IO.

NGOs lead six of the initiatives, making NGOs the second most prominent lead actor type. However, what characterises most of the NGO-led initiatives, and particularly those that are effective, is their proximity to a larger organisation. The NAP Global Network receives support from the German and the US governments. Similarly, two city-initiatives, the 100 Resilient Cities and the Asian Cities Climate Change Resilience Network, receive financial and organisational support from the Rockefeller Foundation, a large private donor. This implies that it is hard to achieve effective outcomes without leadership or direct support from a large actor. The one outlier, the Resilient Africa Network, is a consortium of research organisations. However, even here, the initiative is funded by the US Agency for International Development.

The analysis also shows that there is no clear link between the number of actor types participating in an initiative and its effectiveness. This indicates that there is no solid formula for the perfect number of actor types and that each initiative seeks its own balance (see also Pattberg and Widerberg 2016). However, initiatives with active participation from actors from the Global South tend to be more effective, making up two-thirds of the total. This might indicate that broad participation is important for effectiveness, although contrasting results have been discussed elsewhere (see e.g. Liese and Beisheim 2014). 


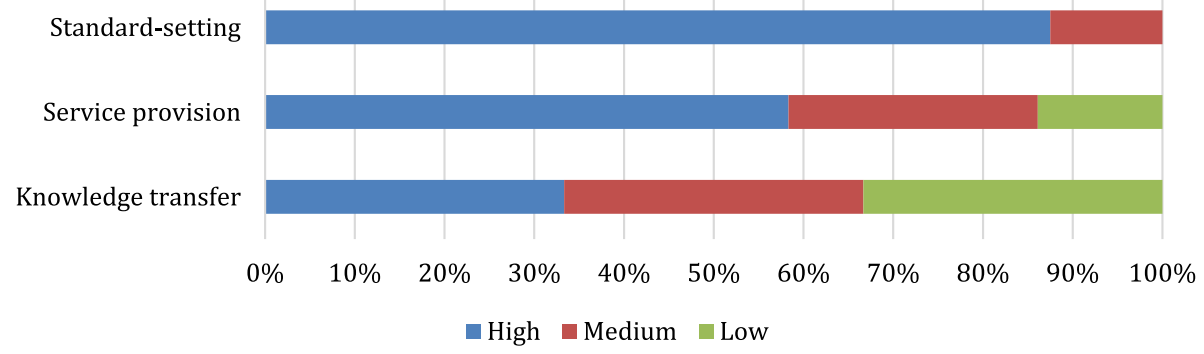

Fig. 4 Aggregated effectiveness scoring based on 'type of provision'

Furthermore, because climate change adaptation mainly affects those that are the most vulnerable (IPCC 2015), many initiatives are connected to areas in the global south.

\subsection{Process}

The effectiveness of the initiatives does not vary across issue areas or policy fields. What did explain the variance in effectiveness was the type of provision, which can be structured in a typology of three core functions (Liese and Beisheim 2014:38) that represent broader categories of the governance functions above (Fig. 1). Initiatives can be providers of 'knowledge transfer', 'service provision' and/or 'standard-setting'. Knowledge-transfer initiatives are those that generate new expertise and provide forums for generation and dissemination of knowledge through, for example, exchange of new practices. Service-provision initiatives are those where the main function is to distribute resources and services, for example funding. Standard-setting initiatives aim to establish new rules and setting minimum-standards for its members or a broader community.

In total, 18 initiatives are primarily knowledge-transfer providers, 18 focus on providing services, and 4 primarily set standards. Figure 4 shows that standard-setting initiatives to a larger extent achieve high effectiveness, with three of four initiatives being effective. Eight service-providing initiatives are effective. And lastly, only eight out of 17 knowledge-transfer initiatives are effective. This indicates that standard-setting and serviceprovision initiatives have better outcome effectiveness and a higher potential for impact. In contrast, knowledge-transfer initiatives, while good at creating outputs, fail to achieve broader outcomes.

Initiatives with a clear mandate and decision-making structure and a well-staffed secretariat tend to perform better (Liese and Beisheim 2014:28). All initiatives that score high on effectiveness have dedicated staff with at least five full-time equivalent (FTE), either at a standalone secretariat or hosted by a larger IO. In terms of variance between the type of provision, service-providing initiatives focus mainly on funding, participatory management and institutional capacity building. Standard-setting initiatives tend to focus on norm- and agenda-setting and advocacy and campaigning. The primary function of the majority of knowledge-transfer initiatives is knowledge dissemination. The latter have a stronger focus on creating outputs without a clear mandate to achieve effective outcomes. In contrast, both service-providing and, in particular, standard-setting initiatives require a more stringent management strategy and clearer decision-making procedures (See e.g. Beisheim and 
Liese 2014). Thus, the better and more efficient the process management, the more effective is the initiative.

In contrast, initiatives that lack strong process management fail to achieve effective outcomes even though they are led by a strong orchestrator. For example, the Global Alliance for Climate-Smart Agriculture (GACSA) initiative is led by the Food and Agriculture Organization of the United Nations (FAO), and despite having a high profile and being hosted by an IO, its effectiveness is hampered by a lack of dedicated staff. GACSA is only supported partly by FAO staff and therefore lacks a proper secretariat with a clear governance and facilitation unit. Beisheim and Liese (2014) argue, however, that most initiatives undergo tremendous changes during their first years of existence. Thus, an ability for organisational learning and capacity building could improve effectiveness through process management over time.

\subsection{Institutional design}

In contrast to Beisheim and Liese (2014) and Szulecki et al. (2011), obligation was found not to be as strongly correlated with effectiveness. While those initiatives with binding rules and quantified targets tend to be more effective, this was not a precondition for effectiveness. Of the 15 initiatives that scored high on effectiveness only three had binding rules and for another three initiatives, rules were contingent. A majority of the effective initiatives did not impose binding targets or conditionalities or apply quantified targets in order to achieve effectiveness. This can partially be explained by the nature of transnational adaptation initiatives, which focus more on soft governance. In terms of type of provision, however, standard-setting initiatives, which achieve a higher level of effectiveness, depend to a larger extent on binding rules and conditionality, where compliance mechanisms were seen as more important for operations than for knowledge-transfer and service-provision initiatives.

There is a strong connection between effectiveness and initiatives with a clear governance structure, strategic plans and regular external or internal evaluation reports. All 15 initiatives that scored high on goal attainment have strategic plans and systems for monitoring and evaluation. Contrary to other research (Homkes 2011; Liese and Beisheim 2014), whether initiatives are independent or hosted by a larger IO made no difference in effectiveness. While it could be argued that initiatives hosted by an IO do not have an independent mandate, one interviewee stated that their work would not have existed without the funding commitment and access to knowledge resources of the IO.

In all cases where initiatives scored low on effectiveness, rules were found to be vague and broad so that they impede compliance, monitoring, reporting, and evaluation, and consequently limit progress towards achieving the set objectives.

\subsection{Context}

A way to understand the role of context for the effectiveness of an adaptation initiative is to assess its alignment with international regimes, including the UNFCCC, the Agenda 2030 and the Sendai Framework for Disaster Risk Reduction as well as coordination between initiatives working in a similar issue area.

In terms of adherence to the UNFCCC, an interesting finding emerges. Of the 15 initiatives that score high on both output and outcome efficiency, six are committed or highly committed to the UNFCCC process. This means that they see the UNFCCC adaptation regime 
as instrumental for their success. What seems to be equally important for effective initiatives is adherence to other international regimes, including Agenda 2030, the Sendai Framework for Disaster Risk Reduction, UN-Habitat, and the UN Convention on Biological Diversity (UNCBD). While there are overlaps, several effective initiatives tend to adhere to these regimes to a larger extent than the UNFCCC. For example, the R4 Rural Resilience Initiative and the Making Cities Resilient Campaign do not operate closely to the UNFCCC, while Sustainable Agriculture Network and the Resilient Africa Network largely operate outside its scope, but have nevertheless been successful.

Another important context-related aspect is a meta-governance perspective, which relates to organisation of self-organisation within networked governance (Jessop 2011). In other words, how do initiatives coordinate between themselves within a specific issue area? This was an important factor for effectiveness. Of the 15 effective initiatives, 12 coordinate with other initiatives in their issue area, which indicates that transnational adaptation is a manifestation of networked governance (Treib et al. 2007; Jordan 2008). Particularly, initiatives focusing on cities and regions often complement each other, seeking to fill in gaps rather than replicating each other's work. This networked relationship can take the form of a Memorandum of Understanding (MoU) where there is overlap (such as between C40 and 100 Resilient Cities), through joint initiatives (such as Transformative Actions Program or the Cities Climate Finance Leadership Alliance), or through joint work under the UN-Habitat platform (See also paper from Papin 2019).

\section{Conclusion}

This paper assessed the effectiveness of 40 initiatives that are governing adaptation across borders and that include non-state actors, through an analysis of outputs produced and the outcomes these have led to. It asked: do transnational adaptation initiatives achieve their stated goals and objectives, and which factors can explain their ability to contribute to effective climate change adaptation? The assessment found that while almost two-thirds of the initiatives produced effective outputs, only one-third achieved effective outcomes, in the sense of leading to substantial change in behaviour of targets.

Based on the discussion of results above, five conclusions can be made in relation to explaining the effectiveness of transnational adaptation initiatives. First, orchestration is key: more important than optimal partner mix, strong leadership is vital for effective adaptation outcomes. Even those initiatives that were not led by an orchestrator often had a powerful supporting actor, such as an international organisation, government, or large private foundation. This indicates that orchestration is not only a top-down technique, but that it also operates from the bottom-up where NGOs and other non-state actors are actively seeking orchestration (Abbot et al. 2015).

Second, effectiveness requires good process management. A powerful orchestrator is not enough if there is not an independent secretariat and full-time staff with a clear decision-making structure and the capacity and funding to achieve the objectives.

Third, the type of provision affects where initiatives put emphasis on effectiveness. Knowledge-transfer initiatives are good at producing outputs, but many fail to achieve strong outcomes unless their mandate is broader than knowledge dissemination, while service-providing and standard-setting initiatives, which require a more stringent management strategy and clearer decision-making procedures, tend to focus more on outcomes. Fourth, 
as in previous literature (Beisheim and Liese 2014; Szulecki et al. 2011), high level of institutionalisation matters for effectiveness.

Fourth, a low level of institutionalisation is the best explanatory factor for low effectiveness. Those initiatives that scored low had no binding rules, lacked quantified targets and had no external systems for monitoring.

Lastly, from a meta-governance perspective, initiatives that are internally coordinating in their issue area, seeking overlaps and complementarity rather than competition, are more effective. In addition, effectiveness of transnational adaptation initiatives goes beyond adherence to the UNFCCC. Global platforms such as the Global Climate Action Agenda, the Sustainable Development Partnerships Platform, the Small Island States Partnership Framework, among others, are important arenas for increased coordination and stronger adherence to global adaptation-related regimes (Hsu et al. 2015).

However, a majority of the initiatives were not found to be highly effective when it comes to producing outcomes. Why? One issue could be a lack of private sector involvement. Another possible explanation is the lack of long-term and sustainable funding. For example, if a project is successful and changes the behaviour of targeted communities, there is a risk that the same communities return to unsustainable practices if there is not enough focus on capacity building and community development for the long term. In addition, some initiatives can be effective with regard to other objectives and do not always prioritise their adaptation objectives. Furthermore, there is a discrepancy between the nature of the problem (climate change) in contrast to the internal objectives of an initiative. Climate change is a complex issue, that can be called a malign problem (Miles et al. 2001), with several competing interests and solutions, as well as complex relationships between adaptation and mitigation. A specific initiative might focus on a small, often manageable, part of this highly complex issue, and while it can be effective in achieving its own objectives, it might not contribute more broadly to solving the climate change problem. For example, even though the SAN initiative achieves effective adaptation outcomes, despite decades of efforts by state and non-state actors alike, the production of many agricultural commodities continues to be defined by smallholder poverty (DeFries et al. 2017).

Nevertheless, given that transnational adaptation initiatives are often relatively small in scale and reach, and often focus on softer governance, their main impact may be found in how they contribute to the broad processes of transformation of the climate change regime rather than their individual effects (see e.g. Hoffmann 2011; Bulkeley et al. 2014).

There are significant limitations to assessing effectiveness of transnational governance initiatives. Assessing effectiveness of a medium-n sample through a set of qualitative indicators leaves out issues such as social conflict, economic interests, norms, hierarchies and identities that shape the context for governance. Social and political conflicts are inseparable from the process of climate adaptation. Furthermore, this analysis was done at a fixed point in time. However, transnational initiatives change frequently (Ulbert 2013). A different point in time might have given different answers. Similarly, as adaptation is contextspecific, effective outcomes that lead to desired change in behaviour in one area could have negative spill-over effects elsewhere (Atteridge and Remling 2018; Hedlund et al. 2018) and lead to maladaptation. Thus, research that complements this paper's approach through, inter alia, political economy and equity perspectives on transnational adaptation governance is necessary to provide a more complete picture of effectiveness of transnational adaptation initiatives. 
Acknowledgements This research has been funded by the Swedish Research Council Formas (Grant No. 2015-344). I am also grateful to Richard Klein, Frank Biermann, Sander Chan and two anonymous reviewers for valuable suggestions on early versions of this paper.

\section{Compliance with ethical standards}

Conflict of interest The author declares no conflict of interest.

Open Access This article is distributed under the terms of the Creative Commons Attribution 4.0 International License (http://creativecommons.org/licenses/by/4.0/), which permits unrestricted use, distribution, and reproduction in any medium, provided you give appropriate credit to the original author(s) and the source, provide a link to the Creative Commons license, and indicate if changes were made.

\section{References}

Abbott, K. W. (2012). The transnational regime complex for climate change. Environment and Planning C: Government and Policy, 30(4), 571-590.

Abbott, K. W., Genschel, P., Snidal, D., \& Zangl, B. (2015). Orchestrating global governance: From empirical findings to theoretical implications. In K. W. Abbott, et al. (Eds.), International organizations as orchestrators. Cambridge: Cambridge University Press.

Abbott, K. W., Keohane, R. O., Moravcsik, A., Slaughter, A.-M., \& Snidal, D. (2000). The concept of legalization. International Organization, 54, 401-419.

Abbott, K. W., \& Snidal, D. (2009). Strengthening international regulation through transmittal new governance: overcoming the orchestration deficit. Vanderbilt Journal of Transnational Law, 42, 501.

Adger, W. N., Arnell, N. W., \& Tompkins, E. L. (2005). Successful adaptation to climate change across scales. Global Environmental Change, 15(2), 77-86.

Andonova, L. B. (2014). Boomerangs to Partnerships? Explaining State Participation in Transnational Partnerships for Sustainability. Comparative Political Studies, 47(3), 481-515. https://doi. org/10.1177/0010414013509579.

Andonova, L. B., Betsill, M. M., \& Bulkeley, H. (2009). Transnational climate governance. Global Environmental Politics, 9(2), 52-73.

Atteridge, A., \& Remling, E. (2018). Is adaptation reducing vulnerability or redistributing it? Wiley Interdisciplinary Reviews: Climate Change, 9(1), e500.

Ayers, J., \& Dodman, D. (2010). Climate change adaptation and development I: The state of the debate. Progress in Development Studies, 10(2), 161-168.

Aylward, S., Stolee, P., Keat, N., \& Johncox, V. (2003). Effectiveness of continuing education in longterm care: A literature review. The Gerontologist, 43(2), 259-271.

Bäckstrand, K. (2008). Accountability of networked climate governance: The rise of transnational climate partnerships. Global Environmental Politics, 8(3), 74-102.

Barham, B. L., \& Weber, J. G. (2012). The economic sustainability of certified coffee: Recent evidence from Mexico and Peru. World Development, 40(6), 1269-1279.

Beisheim, M. (2012). Partnerships for sustainable development: Why and how Rio? 20 must improve the framework for multi-stakeholder partnerships. RP 3. Stiftung Wissenschaft und Politik, German Institute for International and Security Affairs.

Beisheim, M., \& Campe, S. (2012). Transnational public-private partnerships' performance in water governance: Institutional design matters. Environment and Planning C: Government and Policy, 30(4), 627-642.

Beisheim, M., \& Liese, A. (2014). Summing up: Key Findings and avenues for future resaerch. In M. Beisheim \& A. Liese (Eds.), Transnational partnerships-Effectively providing for sustainable development. London: Palgrave Macmillan UK. https://doi.org/10.1057/9781137359537.

Benzie, M., \& Persson, A. (2019). Governing borderless climate risks: Moving beyond the territorial framing of adaptation. International Environmental Agreements: Politics, Law and Economics. https://doi.org/10.1007/s10784-019-09441-y.

Berrang-Ford, L., Ford, J. D., \& Paterson, J. (2011). Are we adapting to climate change? Global Environmental Change, 21(1), 25-33.

Biermann, F., \& Boas, I. (2010). Preparing for a warmer world: Towards a global governance system to protect climate refugees. Global Environmental Politics, 10(1), 60-88. 
Biermann, F., Pattberg, P., Van Asselt, H., \& Zelli, F. (2009). The fragmentation of global governance architectures: A framework for analysis. Global Environmental Politics, 9(4), 14-40.

Bulkeley, H., Andonova, L. B., Betsill, M. M., Compagnon, D., Hale, T., Hoffmann, M. J., et al. (2014). Transnational climate change governance. Cambridge: Cambridge University Press.

Challinor, J. A., Adger, W. N., Benton, G. T., Conway, D., Joshi, M., \& Frame, D. (2018). Transmission of climate risks across sectors and borders. Philosophical Transactions of the Royal Society A: Mathematical, Physical and Engineering Sciences, 376(2121), 20170301. https://doi.org/10.1098/ rsta.2017.0301.

Chan, S., \& Amling, W. (2019). Does orchestration in the Global Climate Action Agenda effectively prioritize and mobilize transnational climate adaptation action? International Environmental Agreements: Politics, Law and Economics. https://doi.org/10.1007/s10784-019-09444-9.

Chan, S., Falkner, R., Goldberg, M., \& van Asselt, H. (2018). Effective and geographically balanced? An output-based assessment of non-state climate actions. Climate Policy, 18(1), 24-35. https://doi. org/10.1080/14693062.2016.1248343.

Cole, D. (2015). Advantages of a polycentric approach to climate change policy. Nature Climate Change, 1, 1. https://doi.org/10.1038/nclimate2490.

Dalberg (2016). Impact evaluation of the $R 4$ rural resilience initiative in Senegal_Final evaluation. https://www.oxfamamerica.org/static/media/files/WFP_Oxfam_R4_Final_Report_English_FINAL .pdf. Accessed 13 March 2018.

DeFries, R. S., Fanzo, J., Mondal, P., Remans, R., \& Wood, S. A. (2017). Is Voluntary certification of tropical agricultural commodities achieving sustainability goals for small-scale producers? a review of the evidence. Environmental Research Letters, 12, 033001.

Derkx, B., \& Glasbergen, P. (2014). Elaborating global private meta-governance: An inventory in the realm of voluntary sustainability standards. Global Environmental Change, 27, 41-50.

Dzebo, A., \& Stripple, J. (2015). Transnational adaptation governance: An emerging fourth era of adaptation. Global Environmental Change, 35, 423-435.

Easton, D. (1965). A systems analysis of political life. New York: Wiley.

Ford, J. D., \& Berrang-Ford, L. (2011). Climate change adaptation in developed nations: From theory to practice (Vol. 42). Berlin: Springer.

Ford, J. D., Berrang-Ford, L., Biesbroek, R., Araos, M., Austin, S. E., \& Lesnikowski, A. (2015). Adaptation tracking for a post-2015 climate agreement. Nature Climate Change, 5(11), 967.

Glasbergen, P. (2010). Global action networks: Agents for collective action. Global Environmental Change, 20(1), 130-141. https://doi.org/10.1016/j.gloenvcha.2009.09.002.

GPSC. (2016). Global platform for sustainable cities booklet. Washington: Global Environmental Facility.

Green, J. F. (2013). Rethinking private authority: Agents and entrepreneurs in global environmental governance. Princeton: Princeton University Press.

Hedlund, J., Fick, S., Carlsen, H., \& Benzie, M. (2018). Quantifying transnational climate impact exposure: New perspectives on the global distribution of climate risk. Global Environmental Change, 52, 75-85. https://doi.org/10.1016/j.gloenvcha.2018.04.006.

Héritier, A., \& Lehmkuhl, D. (2008). The shadow of hierarchy and new modes of governance. Journal of Public Policy, 28(1), 1-17. https://doi.org/10.1017/S0143814X08000755.

Hoffmann, M. J. (2011). Climate governance at the crossroads: experimenting with a global response after Kyoto. Oxford: Oxford University Press.

Homkes, R. (2011). Analysing the role of public-private partnerships in global governance: Institutional dynamics, variation and effects. PhD thesis, The London School of Economics and Political Science (LSE).

Hsu, A., Cheng, Y., Weinfurter, A., Xu, K., \& Yick, C. (2016). Track climate pledges of cities and companies: data transparency is key to accounting for how local governments and the private sector are contributing to global emissions reduction, say Angel Hsu and colleagues. Nature, 532(7599), 303-307.

Hsu, A., Moffat, A. S., Weinfurter, A. J., \& Schwartz, J. D. (2015). Towards a new climate diplomacy. Nature Climate Change, 5, 501-503. https://doi.org/10.1038/nclimate2594.

IPCC. (2015). Climate Change 2015: Synthesis report. Contribution of working groups I, II and III to the fifth assessment report of the intergovernmental panel on climate change (p. 151). Geneva: International Panel on Climate Change.

IPCC. (2018). Summary for policymakers. In: Global warming of $1.5^{\circ} \mathrm{C}$ (32 pp). International Panel on Climate Change, Geneva, Switzerland.

Isoaho, K., \& Surminski, S. (2015). Does it matter what you call it? Reflections on how companies voluntarily disclose their adaptation activities. Centre for climate change economics and policy, Working paper no 236.

Jägers, S. C., \& Stripple, J. (2003). Climate govenance beyond the state. Global Governance, 9, 385. 
Jessop, B. (2011). Metagovernance. In M. Bevir (Ed.), The Sage handbook of governance (pp. 106-123). London: Sage.

Jordan, A. (2008). The governance of sustainable development: Taking stock and looking forwards. Environment and Planning C: Government and Policy, 26(1), 17-33. https://doi.org/10.1068/cav6.

Jordan, A. J., Huitema, D., Hildén, M., van Asselt, H., Rayner, T. J., Schoenefeld, J. J., et al. (2015). Emergence of polycentric climate governance and its future prospects. Nature Climate Change, 5(11), 977982. https://doi.org/10.1038/nclimate2725.

Karlsson-Vinkhuyzen, S. I., \& Vihma, A. (2009). Comparing the legitimacy and effectiveness of global hard and soft law: An analytical framework. Regulation and Governance, 3(4), 400-420.

Keohane, O. R., Haas, P., \& Levy, M. (1993). The effectiveness of international environmental institutions. In M. P. Haas, O. R. Keohane, \& A. M. Levy (Eds.), Institutions for the earth. Sources of effective international environmental protection (pp. 3-24). Cambridge: MIT Press.

Khan, M. R. (2013). Toward a binding climate change adaptation regime: A proposed framework. London: Routledge.

Khan, M. R., \& Roberts, J. T. (2013). Adaptation and international climate policy. Wiley Interdisciplinary Reviews: Climate Change, 4(3), 171-189.

Klein, R. J. T., Adams, K. M., Dzebo, A., \& Siebert, K. C. (2017). Advancing climate adaptation practices and solutions: emerging research priorities. SEI Working Paper 2017-07. Stockholm, Sweden.

Liese, A., \& Beisheim, M. (2014). Research design: Measuring and explaining the effectiveness of PPPs. In M. Beisheim \& A. Liese (Eds.), Transnational partnerships-Effectively providing for Sustainable development. London: Palgrave Macmillan. https://doi.org/10.1057/9781137359537.

Litta, H. (2011). Regimes in Southeast Asia. Berlin: Springer.

Madajewicz, M., Tsegay, H. A., Norton, M., \& (2013). Managing risks to agricultural livelihoods: Impact evaluation of the Harita program in Tigray, Ethiopia, 2009-2012. Oxfam America Evaluation Report.

Magnan, A. K., \& Ribera, T. (2016). Global adaptation after Paris. Science, 352(6291), 1280-1282.

Milder, C. J., \& Newsom, D. (2015). SAN/Rainforest Alliance Impacts Report Evaluating the Effects of the SAN/Rainforest Alliance Certification System on Farms, People, and the Environment. New York: Rainforest Alliance, Cuahtemoc: Sustainable Agriculture Network.

Miles, E. L., Andresen, S., Carlin, E. M., Skjaerseth, J. B., Underdal, A., \& Wettestad, J. (2001). Environmental regime effectiveness: Confronting theory with evidence. Cambridge: Mit Press.

Mitchell, B. R. (2008). Evaluating the performance of environmental institutions: What to evaluate and how to evaluate it? In R. O. Young, A. L. King, \& H. Schroeder (Eds.), Institutions and environmental change: Principal findings, applications, and research frontiers (pp. 79-114). London: MIT Press.

Newell, P., Pattberg, P., \& Schroeder, H. (2012). Multiactor governance and the environment. Annual Review of Environment and Resources, 37(1), 365-387. https://doi.org/10.1146/annurev-envir on-020911-094659.

Ochieng, B. O., Hughey, K. F., \& Bigsby, H. (2013). Rainforest alliance certification of Kenyan tea farms: a contribution to sustainability or tokenism? Journal of Cleaner Production, 39, 285-293.

Paavola, J., \& Adger, W. N. (2006). Fair adaptation to climate change. Ecological Economics, 56(4), 594-609.

Papin, M. (2019). Transnational municipal networks: Harbingers of innovation for global adaptation governance? International Environmental Agreements: Politics, Law and Economics. https://doi.org/10.1007/ s10784-019-09446-7.

Pattberg, P., Biermann, F., Chan, S., \& Mert, A. (2012). Public-private partnerships for sustainable development: Emergence, influence and legitimacy. Cheltenham: Edward Elgar Publishing.

Pattberg, P., \& Widerberg, O. (2016). Transnational multistakeholder partnerships for sustainable development: Conditions for success. Ambio, 45(1), 42-51.

Persson, А. \& Dzebo, A. (2019). Introduction to the special issue: Global and transnational governance of climate adaptation. International Environmental Agreements: Politics, Law and Economics. https://doi. org/10.1007/s10784-019-09440-z.

Persson, A., Klein, R., Siebert, C., Atteridge, A., Müller, B., Hoffmeister, J., Lazarus, M., \& Takama, T. (2009). Adaptation Finance Under a Copenhagen Agreed Outcome. Stockholm Environment Institute Research Report. SEI: Stockholm. https://www.sei.org/mediamanager/documents/Publications/ SEI-ResearchReport-PerssonA-AdaptationFinanceUnderACopenhagenAgreedOutcome-2009.pdf. Accessed 29 Oct 2017.

Roger, C., Hale, T., \& Andonova, L. (2015). How do domestic politics shape participation in transnational climate governance? BSG Working Paper, 2015/00.

Roggero, M., Kähler, L., \& Hagen, A. (2019). Strategic cooperation for transnational adaptation: Lessons from the economics of climate change mitigation. International Environmental Agreements: Politics, Law and Economics. https://doi.org/10.1007/s10784-019-09442-x. 
SAN (2016). Our work. Sustainable Agriculture Network. New York: Rainforest Alliance, Cuahtemoc: Sustainable Agriculture Network.

Schout, A., \& Jordan, A. (2005). Coordinated European governance: Self-organizing or centrally steered? Public Administration, 83(1), 201-220.

Skjaerseth, J. B., Stokke, O. S., \& Wettestad, J. (2006). Soft law, hard law, and effective implementation of international environmental norms. Global Environmental Politics, 6(3), 104-120.

Southern Voices (2015a). Joint principles for adaptation: A civil society initiative to promote effective and equitable adaptation to climate change. CARE Denmark.

Southern Voices (2015b). Putting principles into practice: Civil society experiences from across the world of using the Joint Principles for Adaptation. CARE Denmark.

Sovacool, B. K., Linnér, B.-O., \& Goodsite, M. E. (2015). The political economy of climate adaptation. Nature Climate Change, 5(7), 616.

Szulecki, K., Pattberg, P., \& Biermann, F. (2011). Explaining variation in the effectiveness of transnational energy partnerships. Governance, 24(4), 713-736.

Tompkins, E. L., Vincent, K., Nicholls, R. J., \& Suckall, N. (2018). Documenting the state of adaptation for the global stocktake of the Paris Agreement. Wiley Interdisciplinary Reviews: Climate Change, 9(5), e545. https://doi.org/10.1002/wcc.545.

Treib, O., Bähr, H., \& Falkner, G. (2007). Modes of governance: towards a conceptual clarification. Journal of European Public Policy, 14(1), 1-20. https://doi.org/10.1080/135017606061071406.

Ulbert, C. (2013). How to hit a moving target. Assessing the effectiveness of public-private partnerships. In H. Hegemann, R. Heller, \& M. Kahl (Eds.), Studying effectiveness in international relations. A guide for students and scholars (pp. 11-122). Opladen: Barbara Budrich.

Underdal, A. (2001). Methods of analysis. In E. L. Miles, S. Andresen, E. M. Carlin, J. B. Skjaerseth, A. Underdal, \& J. Wettestad (Eds.), Nvironmental regime effectiveness: Confronting theory with evidence. London: Mit Press.

Underdal, A., \& Young, O. R. (Eds.) (2004). Research strategies for the future. In Regime consequences (pp. 361-380). Springer.

UNEP. (2015). Climate commitments of subnational actors and business: A quantitative assessment of their emission reduction impact. Nairobi: United Nations Environment Programme.

UNFCCC. (2012). National adaptation plans: Tecnhical guidelines for the national adaptation plan process. LDC Expert Group. Bonn:United Nations Framework Convention on Climate Change.

UNFCCC. (2015). Paris Agreement. United Nations Framework Convention on Climate Change. https:// unfccc.int/sites/default/files/english_paris_agreement.pdf. Accessed 15 June 2017.

UNFCCC. (2017). Initiatives in the area of human settlements and adaptation. FCCC/SBSTA/2017/INF.3. Bonn: United Nations Framework Convention on Climate Change.

UNFCCC. (2018). Joint reflections note by the presiding officers of the ad hoc working group on the Paris agreement, the subsidiary body for scientific and technological Advice and the subsidiary body for implementation. Addendum 3. APA-SBSTA-SBI.2018.Informal.2.Add.3. Bonn: United Nations Framework Convention on Climate Change.

Vogel, D. (2008). Private global business regulation. Annual Review Political Science, 11, 261-282.

WFP and Oxfam (2017). R4 Rural Resilience Initiative. World Food Prgramme and Oxfam Americe. https ://docs.wfp.org/api/documents/b9a3d33bd9974e5aaf01b11a3e3da410/download/ Accessed: 13 March 2018.

Widerberg, O., \& Pattberg, P. (2014). International cooperative initiatives in global climate governance: Raising the ambition level or delegitimizing the UNFCCC? Global Policy, 6, 45-56. https://doi. org/10.1111/1758-5899.12184.

Young, R. O. (2004). Institutions and the growth of knowledge: Evidence from international environmental regimes. International Environmental Agreements, 4(2), 215-228.

Young, R. O. (2011). Effectiveness of international environmental regimes; Existing knowledge, cuttingedge themes, and research strategies. PNAS, 108(50), 19853-19860.

Publisher's Note Springer Nature remains neutral with regard to jurisdictional claims in published maps and institutional affiliations. 